\title{
Prenatal exposure to cocaine in rats: Lack of long-term effects on locomotion and stereotypy
}

\author{
MAGDA GIORDANO \\ University of Cincinnati Medical Center, Cincinnati, Ohio \\ CAROLE A. MOODY \\ State University of New York, Binghamton, New York \\ EVE M. ZUBRYCKI \\ University of Cincinnati Medical Center, Cincinnati, Ohio \\ LAURA DRESHFIELD \\ Miami University, Oxford, Ohio \\ and \\ ANDREW B. NORMAN and PAUL R. SANBERG \\ University of Cincinnati Medical Center, Cincinnati, Ohio
}

\begin{abstract}
Cocaine, a psychomotor stimulant, is known to produce sympathomimetic as well as psychological effects. Its widespread use among women of reproductive age has prompted a variety of studies aimed at detecting effects on offspring. However, the results remain controversial. The present study was designed to evaluate the effect of prenatal exposure to cocaine on the ontology of behavior. Emphasis was given to cocaine's effects on the development of the dopaminergic system. Pregnant rats were subcutaneously injected with either cocaine hydrochloride $(30 \mathrm{mg} / \mathrm{kg})$ or vehicle from Day 12 to Day 21 of gestation. After birth, pups were weighed, measured, and evaluated on a variety of developmental cues. Sixty days after birth, locomotor behavior was assessed, as well as the response to d-amphetamine and cocaine. In the cocaine-exposed pups, no evidence of gross morphological or developmental deficits was found, nor was there any differential response to amphetamine or cocaine. The relevance of various parameters such as dose, time of exposure, time of testing, and administration route is discussed.
\end{abstract}

Cocaine produces a variety of local and systemic pharmacological actions (Ritchie \& Greene, 1980). In the autonomic nervous system, it produces vasoconstriction, mydriasis, and cardioacceleration, and, as a consequence, blood pressure is increased. In the central nervous system, cocaine acts as a stimulant and affects monoaminergic neurotransmission (Gold, Washton, \& Dackis, 1985).

It has been reported that cocaine can penetrate through the placenta and accumulate in fetal tissue (Shah, May, \& Yates, 1980), making it possible for cocaine to produce effects directly on the fetus. Thus, it is possible that the use of cocaine by women of reproductive age may have an adverse effect on their offspring (Lifschitz, Walters, \& Wilson, 1986; MacGregor et al., 1987). However, the

This work was supported in part by PHS Grant NS25647 to Paul R. Sanberg. We are indebted to Robert A. Frank for support and advice and to Roger Nicholson for technical assistance. Correspondence should be addressed to Magda Giordano, Division of Neuroscience, Department of Psychiatry, University of Cincinnati Medical Center, 231 Bethesda Ave., Cincinnati, OH 45267-0559. results from animal studies are controversial (e.g., Feigenbaum \& Yanai, 1984; Mahalik, Gautieri, \& Mann, 1980). Mahalik et al. (1980) reported several birth defects after single injections of cocaine hydrochloride $(60 \mathrm{mg} / \mathrm{kg})$ during Days 7-12 of gestation in CF-1 mice. Conversely, Fantel and Macphail (1982) administered $50 \mathrm{mg} / \mathrm{kg}$ of cocaine hydrochloride during Days 8-12 of gestation to Swiss Webster mice and found all the fetuses to be normal upon external, internal, and skeletal examination. No differences were found in the weights of fetal tissues in comparison to controls. Although strain differences may account for these discrepant results, it is apparent that cocaine's effects on fetal development in utero are not well documented.

In addition to cocaine's potential as a teratogenic agent, the central effects of cocaine may alter the normal development of the neurotransmitter systems upon which it acts. It is known that cocaine blocks dopamine reuptake, facilitates dopamine release, and activates tyrosine hydroxylase (Dackis \& Gold, 1985; Gold et al., 1985). The dopaminergic system is associated with a variety of 
locomotor and stereotypical behaviors (Iversen, 1977). Furthermore, it has been suggested that after prenatal exposure to drugs that modulate dopaminergic neurotransmission, there are alterations in behavior (Middaugh \& Zemp, 1985).

The present study was designed to examine the longterm behavioral effects of prenatal exposure to cocaine in rat pups. Pups were evaluated according to the onset of various developmental cues, nocturnal spontaneous locomotor activity, and stereotypic response to the indirectly acting dopamine agonist d-amphetamine and to cocaine. A preliminary report has been presented elsewhere (Moody et al., 1988).

\section{METHOD}

\section{Animals and Housing}

Subjects were 4 pregnant female Sprague-Dawley rats and their offspring. They were kept on a 12:12 h reversed dark:light schedule and were given food and water ad lib.

\section{Drugs}

Two of the pregnant females were subcutaneously injected with $30 \mathrm{mg} / \mathrm{kg}$ cocaine hydrochloride (Sigma Chemical Co., St. Louis, MO) dissolved in normal saline. Control animals were subjected to the same conditions, but received the vehicle only. Injections were given from Day 12 until Day 21 of gestation. Twenty-four days after birth, all litters received intraperitoneal injections of d-amphetamine $(4 \mathrm{or} 8 \mathrm{mg} / \mathrm{kg}$, Sigma Chemical Co.), cocaine hydrochloride (30 mg/kg, Sigma Chemical Co.), and normal saline (in a volume of $1 \mathrm{mg} / \mathrm{kg}$ ). All drugs were dissolved in normal isotonic saline.

\section{Procedure}

The lengths and weights of the pups were measured at birth and once every 5 days, for their first 20 days of life. The pups were monitored for appearance of pinna detachment, eye opening, righting reflex, negative geotaxis, pivoting, and startle response. At 24 days of age, the pups were weaned and separated into individual cages. On consecutive days, the stereotypic response to d-amphetamine, cocaine hydrochloride, and normal saline was visually evaluated, using a rating scale modified from that of Creese and Iversen (1973). Briefly, on a scale from 0 to 6, a score of 2 indicates an active animal with bursts of stereotyped sniffing or rearing, whereas a score of 4 indicates stereotyped sniffing or rearing maintained in one location. The animals were observed in their home cages beginning $10 \mathrm{~min}$ after injection, every $10 \mathrm{~min}$ for $120 \mathrm{~min}$ for amphetamine and for $80 \mathrm{~min}$ for cocaine. All litters received all drugs and all doses. One control and one experimental litter were tested each day. Each litter was divided into two groups, each receiving the drug or vehicle only. Forty-eight hours later, the animals that had received the vehicle received the drug and vice versa, and the behaviors were assessed as before.

\section{Apparatus}

Spontaneous nocturnal activity was analyzed beginning 60 days after birth by means of the Digiscan Animal Activity Monitor (Omnitech Electronics, Columbus, $\mathrm{OH}$ ), which has been described previously (Sanberg, Hagenmeyer, \& Henault, 1985). The animals were sequentially selected from each litter and placed in the monitor at 9:00 a.m., and their activity was measured for $1-\mathrm{h}$ periods.

\section{Statistical Analysis}

For all measures except stereotypic responses, comparisons were made between group means using a $t$ test for independent measures. For stereotypic responses, groups were compared to their own control session, using a $t$ test for correlated measures (Winer, 1971).

\section{RESULTS}

All 52 pups survived throughout the length of the study. Developmental cues appeared at the same rate in all animals, regardless of the group to which they belonged. Righting reflexes were evident from Day 6; pinna detachment was observed at Day 9; eye opening at Day 12; negative geotaxis and pivoting at Day 9; acoustic startle at Day 13. Weight and length of the pups were similar for all groups.

Both control as well as cocaine-treated pups showed a significant increase in stereotypic behavior after the administration of either 4 or $8 \mathrm{mg} / \mathrm{kg}$ of amphetamine (Figures 1 and 2). However, no differences in spontaneous nocturnal activity were detected between groups (Table 1). Responses to amphetamine and cocaine were compared to each group's own control session. Both control and cocaine-exposed pups responded similarly to all drugs administered. No stereotypical movements were detected in any group after cocaine administration (data not shown).

\section{DISCUSSION}

The present study suggests that prenatal exposure to cocaine at least during the last week of gestation did not alter either the time of onset of developmental cues or the normal pattern of spontaneous locomotor

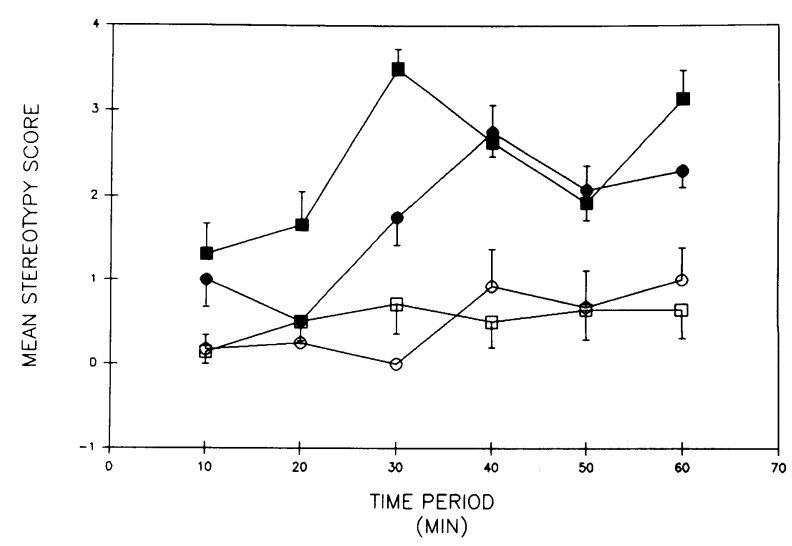

Figure 1. Effect of d-amphetamine $(4 \mathrm{mg} / \mathrm{kg})$ on stereotypy in rats treated prenatally with cocaine. Rats were treated with cocaine as described in methods. At 60 days after birth, rats were administered amphetamine and stereotypy measured at 10-min intervals for $60 \mathrm{~min}$ in home cages. Values represent mean $\pm S E M$ stereotypy scores from rats. The control group showed a significant difference between vehicle and amphetamine in Period $1[t(12)=3.426, p<.01]$, Period $2[t(11)=2.721, p<.02]$, Period $3[t(13)=7.948, p<$ $.001]$, Period $4[t(13)=4.979, p<.001]$, Period $5[t(13)=3.479$, $p<.005]$, and Period $6[t(13)=6.21, p<.001]$. The experimental group showed a significant difference between vehicle and amphetamine in Period $1[t(11)=2.278, p<.05]$, Period $3[t(11)=$ 5.011, $p<.001]$, Period $4[t(11)=5.011, p<.001]$, Period 5 $[t(11)=4.529, p<.002]$, and Period $6[t(11)=5.204, p<.001]$. Circles represent the scores from cocaine-treated animals, and squares represent scores from the control group. Filled circles or squares represent the response to amphetamine ( $4 \mathrm{mg} / \mathrm{kg}$ ), and empty circles or squares represent the response to vehicle only. 


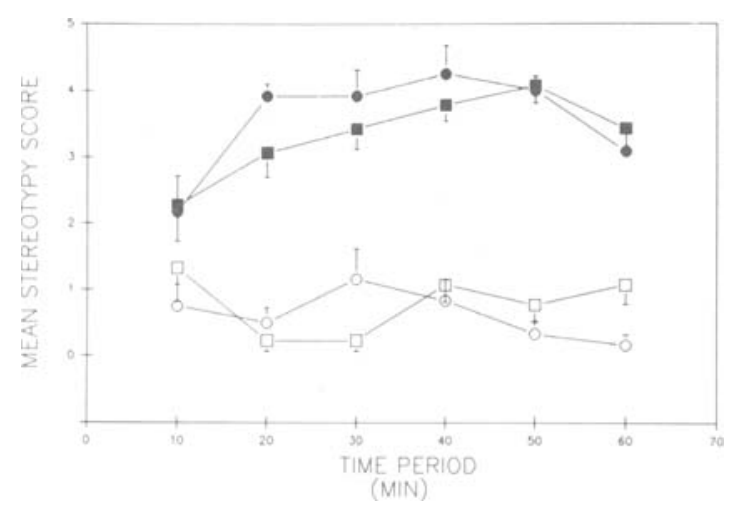

Figure 2. Effect of d-amphetamine $(8 \mathrm{mg} / \mathrm{kg})$ on stereotypy in rats treated prenatally with cocaine. The control group showed a significant difference between vehicle and amphetamine in Period 2 $[t(12)=7.015, p<.001]$, Period $3[t(12)=9.948, p<.001]$, Period $4[t(12)=8.75, p<.001]$, Period $5[t(12)=9.992, p<.001]$, and Period $6[t(12)=8.413, p<.001]$. The experimental group showed a significant difference between vehicle and amphetamine in Period $1[t(10)=3.614, p<.05]$, Period $2[t(11)=17.703$, $p<.001]$, Period $3[t(11)=5.109, p<.001]$, Period $4[t(11)=$ 8.20, $p<.001]$, Period $5[t(11)=14.31, p<.001]$, and Period 6 $[t(11)=6.713, p<.001]$. Circles represent the scores from cocainetreated animals, and squares represent scores from the control group. Filled circles or squares represent the response to amphetamine $(8 \mathrm{mg} / \mathrm{kg}$ ), and empty circles or squares represent the response to the vehicle only.

activity in rat pups. In addition, the results from the experiments with d-amphetamine suggest that prenatal exposure to cocaine did not produce long-term alterations in the sensitivity to dopamine-mediated behaviors.

Human studies concerned with teratogenic effects of cocaine have dealt mainly with prenatal deficits. The common finding of these studies is an increase in the frequency of abruptio placentae, preterm deliveries, and lower birth weight (Bingol et al., 1986; Chasnoff, W. J. Burns, Schnoll, \& K. A. Burns, 1985; Ferreiro, Wong, Townsend, \& Simon, 1988; Lifshitz et al., 1986). With respect to the teratogenic effects of cocaine in animals, our results are similar to those of Fantel and Macphail (1982). They found that prenatal exposure of Sprague-Dawley rats to cocaine even during organogenesis (e.g., Day 7 to Day 12 of gestation) did not result in teratogenic insults. In contrast, CF-1 mice prenatally exposed to cocaine showed various abnormalities at birth (Mahalik et al., 1980). These teratogenic effects of cocaine have been attributed to its vasoconstrictive properties, which result in reduced blood flow to the fetus (Mahalik et al., 1980; Moore, Sorg, Miller, Kay, \& Resnick, 1986)

In the present study, cocaine was administered from Day 12 to Day 21 of gestation, in order to maximize the effect of cocaine on the develop-

Table 1

Digiscan Locomotor Activity: Effect of Prenatal Cocaine Treatment on Spontaneous Nocturnal Locomotor Activity

\begin{tabular}{lcr}
\hline \multicolumn{1}{c}{ Locomotor Variable } & Cocaine-treated & \multicolumn{1}{c}{ Control } \\
\hline Total distance (in.) & $1660 \pm 299$ & $2639 \pm 677$ \\
Movement time (sec) & $328 \pm 41$ & $446 \pm 71$ \\
Vertical activity (counts) & $653 \pm 113$ & $923 \pm 170$ \\
Number of stereotypies (counts) & $390 \pm 53$ & $416 \pm 24$ \\
\hline
\end{tabular}

Note-Pregnant rats treated with cocaine $(30 \mathrm{mg} / \mathrm{kg} \mathrm{s.c.)}$ from gestational Days 12 to 21,60 days postnatal sample offspring, were placed in Digiscan monitors and activity-monitored for $1 \mathrm{~h}$ during peak nocturnal activity period. Values represent mean $\pm S E M$ from 8 (cocaine) or 7 (vehicle) treated rats. ment and function of the striatal dopaminergic system. It has been reported that dopamine is detectable by Day 13 of gestation, developing its functions gradually during the first 4 weeks of postnatal life in the rat (Feigenbaum \& Yanai, 1984; Rosengarten \& Friedhoff, 1979). Chronic treatment of pregnant dams with both dopamine antagonists and $d$-amphetamine have been shown to result in alterations of the dopaminergic system in the offspring (Rosengarten \& Friedhoff, 1979; Spear, Shalaby, \& Brick, 1980). The changes are generally opposite in direction to those seen in chronically treated adults (Spear \& Scalzo, 1986). Rosengarten and Friedhoff (1979) found a decrement in striatal $\left[{ }^{3} \mathrm{H}\right]$ spiroperidol binding and apomorphine stereotypy response in rats prenatally exposed to haloperidol $(2.5 \mathrm{mg} / \mathrm{kg} /$ day $)$ and methyl-p-tyrosine methyl ester $(50 \mathrm{mg} / \mathrm{kg} /$ day). Similarly, Spear et al. (1980) found an increment on amphetamine-induced activity after prenatal exposure (Days 1-21 of gestation) to haloperidol on Days 23-30 after birth, no increment on Days 37-42, and, on Days 47-54, the response was opposite to that of chronic haloperidol-treated controls. Thus, the effects of prenatal haloperidol exposure were detectable 1 month following termination of drug treatment and were apparently dependent on the age of testing (Spear et al., 1980). The prenatal effects of neuroleptics have been shown to occur during gestation Days 15-17; during this period, external influences may permanently alter the state of the dopaminergic system (Miller \& Friedhoff, 1985). Furthermore, it has been suggested that during ontogeny, the response to haloperidol treatment might induce a hyposensitivity rather than a supersensitivity of dopamine receptors (Feigenbaum \& Yanai, 1984).

Prenatal exposure to substances that act as agonists for the dopaminergic system, such as amphetamine, also results in behavioral alterations in the adult animal (Middaugh \& Zemp, 1985). According to BuelkeSam (1986), the profile of behavioral alterations after prenatal exposure to amphetamine is one of subtle alteration. Results across laboratories vary widely, and a consistent pattern of changes is difficult to draw. The neurochemical data collected seems to suggest a complex catecholaminergic and maybe serotonergic mediation of the behavioral alterations (Buelke-Sam, 1986). Although, among other effects, cocaine seems to act as a dopaminergic agonist by blocking reuptake (Gold et al., 1985), it has been suggested that chronic cocaine may induce dopamine depletion at the synaptic level (Dackis \& Gold, 1985). Consequently, one would expect that chronic cocaine treatment during ontogeny might induce hyposensitivity to dopamine agonists due to chronic availability of the neurotransmitter. Alternatively, if there is a depletion of dopamine produced by the chronic cocaine treatment, a dopaminergic hypersensitivity might be expected.

Although it is possible that the dose of cocaine $(30 \mathrm{mg} / \mathrm{kg})$ administered in the present study was insufficient to affect the neurotransmitter systems, subjective effects of cocaine have been reported with doses of 16 mg in humans (Javaid, Fischman, Schuster, Dekirmenjian, \& Davis, 1978). Reductions in the threshold for self-stimulation in adult rats have been obtained with the same dose of cocaine as was used in the present study (Frank, Pommering, \& Nitz, 1980). Furthermore, recent studies have found substantial amounts of cocaine in fetal circulation and in the brain after s.c. administration of 10,20 , and $40 \mathrm{mg} / \mathrm{kg}$ of cocaine, suggesting that this is an adequate route of administration (Spear, Frambes, \& Kirstein, in press).

It would, therefore, appear that short-term perturbation of dopaminergic neurotransmission in utero, at least during the latter period of embryonic development, was insufficient to affect the long-term sensitivity of the dopaminergic system. This is in agreement with previous studies in which prenatal exposure to dopamine agonists, such as amphetamine, did not appear to produce behavioral deficits in the adult animals (BuelkeSam, 1986). Another study has also confirmed that prenatal exposure to cocaine $(20 \mathrm{mg} / \mathrm{kg}$ s.c.) did not alter the offspring's response to postnatal administration of cocaine $(10 \mathrm{mg} / \mathrm{kg})$ or amphetamine $(1 \mathrm{mg} / \mathrm{kg})$ (Sobrian, Burton, Robinson, James, \& Turner, 1988). Therefore, cocaine and d-amphetamine, which increase dopaminergic neurotransmission, do not appear to interfere with the long-term functioning of this system-in contrast to the effects of the neuroleptics, which decrease dopaminergic neurotransmission. Further studies of larger groups of animals, and with tissue and plasma levels of stimulants, are needed to strengthen this conclusion. 


\section{REFERENCES}

Bingol, N., Fuchs, M., Diaz, V., Penchaszadeh, G., Stone, R. K., \& Gromish, P. S. (1986). Teratogenicity of cocaine in humans. Pediatric Research, 20, 337A.

BUELKE-SAM, J. (1986). Postnatal functional assessment following central nervous system stimulant exposure: Amphetamine and caffeine. In E. P. Riley \& C. V. Vorhees (Eds.), Handbook of behavioral teratology (pp. 161-172). New York: Plenum.

Chasnoff, I. J., Burns, W. J., Schnoll, S. H., \& Burns, K. A. (1985). Cocaine use in pregnancy. New England Journal of Medicine, 313, 666-669.

Creese, I., \& Iversen, S. D. (1973). Blockage of amphetamine induced locomotor stimulation and stereotypy in the adult rat following neonatal treatment with 6-OHDA. Brain Research, 55, 369-382.

DackIs, C. A., \&oLD, M. S. (1985). New concepts in cocaine addiction: The dopamine depletion hypothesis. Neuroscience \& Biobehavioral Reviews, 9, 469-477.

FanTel, A. G., \& MacPhaIl, B. J. (1982). The teratogenicity of cocaine. Teratology, 26, 17-19.

Feigenbaum, J. J., \& Yanai, J. (1984). Normal and abnormal determinants of dopamine receptor ontogeny in the central nervous system. Progress in Neurobiology, 24, 191-225.

Ferreiro, D. M., Wong, D. F., Townsend, R., \& Simon, R. P. (1988). Neurologic complications in infants of cocaine-abusing mothers. Neurology, 38 (Suppl. 1), 163.

Frank, R. A., Pommering, T., \& Nitz, D. (1980). The interactive effects of cocaine and imipramine on self-stimulation train-duration thresholds. Pharmacology, Biochemistry, \& Behavior, 30, 1-4.

Gold, M. S., Washton, A. M., \& DACKIS, C. A. (1985). Cocaine abuse: Neurochemistry, pehenomenology, and treatment. In N. J. Kozel \& E. H. Adams (Eds.), Cocaine use in America: Epidemiologic and clinical perspectives (Research Monograph Series No. 61, pp. 130-150). Rockville, MD: National Institute on Drug Abuse.

IVERSEN, S. D. (1977). Brain dopamine systems and behavior. In L. L. Iversen, S. D. Iversen, \& S. H. Snyder (Eds.), Handbook of psychopharmacology: Vol. 8. Drugs, neurotransmitters and behavior (pp. 333-384). New York: Plenum.

JavaID, J. I., Fischman, M. W., SChuster, C. R., DekirmenJian, H., \& DAvis, J. M. (1978). Cocaine plasma concentration: Relation to physiological and subjective effects in humans. Science, 202, 227-228.

Lifschitz, M. H., Walters, F., \& Wilson, G. S. (1986). Perinatal effects of cocaine abuse. Pediatric Research, 20, A2666.

MacGregor, S. N., Keith, L. G., Chasnoff, I. J., Rosner, M. A., Chisum, G. M., Shaw, P., \&inogue, J. P. (1987). Cocaine use during pregnancy: Adverse perinatal outcome. American Journal of Obstetrics \& Gynecology, 157, 686-690.
Mahalik, M. P., Gautieri, R. F., \& Mann, D. E. (1980). Teratogenic potential of cocaine hydrochloride in CF-1 mice. Journal of Pharmaceutical Sciences, 69, 703-706.

MiddAUGH, L. D., \& ZEMP, J. W. (1985). Dopaminergic mediation of long-term behavioral effects of in utero drug exposure. Neurobehavioral Toxicology \& Teratology, 7, 685-689.

Miller, J. C., \& FriedHOFF, A. J. (1985). The window of vulnerability in the ontogeny of the dopamine receptor. Psychopharmacology Bulletin, 21, 683-684.

Moody, C. A., Giordano, M., Zubrycki, E. M., Dreshfield, L., Frank, R. A., Norman, A. B., \& Sanberg, P. R. (1988). Prenatal exposure to cocaine in rats: Effects on locomotion and stereotypy. Society for Neuroscience Abstracts, 14, 963.

MoOre, T. R., SORG, J., Miller, L., KAy, T. C., \& RESNIK, R. (1986). Hemodynamic effects of intravenous cocaine on the pregnant ewe and fetus. American Journal of Obstetrics \& Gynecology, 155, 883-888. Ritchie, J. M., \& Greene, N. M. (1980). Local anesthetics. In A. Goodman-Gilman, L. S. Goodman, \& A. Gilman (Eds.), The pharmacological basis of therapeutics (pp. 300-320). New York: Macmillan.

Rosengarten, H., \& Friedhoff, A. J. (1979). Enduring changes in dopamine receptor cells of pups from drug administration to pregnant and nursing rats. Science, 203, 1133-1135.

Sanberg, P. R., Hagenmeyer, S. H., \& Henault, M. A. (1985). Automated measurement of multivariate locomotor behavior in rodents. Neurobehavioral Toxicology \& Teratology, 7, 87-94.

Shah, N. S., MAY, D. A., \& YATES, J. D. (1980). Disposition of levo- $\left[{ }^{3} \mathrm{H}\right]$ cocaine in pregnant and non-pregnant mice. Toxicology \& Applied Pharmacology, 53, 279-284.

Sobrian, S. K., Burton, L. E., Robinson, N. L., James, H., \& TURNER, L. M. (1988). Neurobehavioral effects of prenatal cocaine exposure. Society for Neuroscience Abstracts, 14, 963.

Spear, L. P., Frambes, N. A., \& Kirstein, C. L. (1989). Fetal and maternal brain and plasma levels of cocaine and benzoylecgonine following chronic subcutaneous administration of cocaine during gestation in rats. Psychopharmacology, 97, 427-431.

SPEAR, L. P., \& SCAlzo, F. M. (1986). Behavioral, psychopharmacological, and neurochemical effects of chronic neuroleptic treatment during development. In E. P. Riley \& C. V. Vorhees (Eds.), Handbook of behavioral teratology (pp. 173-184). New York: Plenum.

Spear, L. P., Shalaby, I. A., \& Brick, J. (1980). Chronic administration of haloperidol during development: Behavioral and psychopharmacological effects. Psychopharmacology, 70, 47-58.

WINER, B. J. (1971). Statistical principles in experimental design. New York: McGraw-Hill.

(Manuscript received May 27, 1989). 